\title{
The Effect of Bottle Laws on Income: New Empirical Results
}

\begin{abstract}
Eleven U.S. states have "bottle laws", deposit-refund programs that combine a consumption tax with a recycling rebate. When states set the bottle deposit low enough it becomes a tax on high wage earners, for whom the opportunity cost of their time prevents them from returning containers for their deposit. However, this bottle deposit will still be high enough that harvesting recyclables provides employment for low wage earners. Using individual data on observed cash recycling behavior, this paper shows that an unintended consequence of bottle laws is that they have the potential to increase the incomes of very low wage workers.
\end{abstract}




\section{Introduction}

This paper reports the results of an empirical study of an unintended consequence, the transfer of income to low income households, of the use of bottle deposit laws to promote consumer recycling. Eleven U.S. states have enacted "bottle laws” which apply a deposit-refund system to the purchase of beverage containers. A bottle law is one of the few examples of an environmental protection policy that takes advantage of the price system. ${ }^{1}$ A classic Pigouvian tax requires a consumer to pay a fee at the time of disposal that is equal to the marginal damage caused by the disposal. A deposit-refund program on beverage containers combines a consumption tax with a rebate for recycling. A Pigouvian tax creates an incentive for consumers to dispose illegally. A deposit-refund, on the other hand, creates an incentive for proper disposal. Putting a bounty on trash is the most efficient way of internalizing the external costs of waste disposal. One of the most general models of a deposit-refund program is described in Fullerton and Wolverton (2000). ${ }^{2}$ Because deposit-refund programs encourage recycling, the deposit-refund literature is a subset of the literature on recycling.

Within the recycling literature various studies have examined the relationship between income level and education level and the effect of income and education level on voluntary and curbside recycling. Callan and Thomas (1997) use community level data to exploit differences in community characteristics. They find that income and education both increase recycling quantities. Duggal et al. (1991) also find that higher income and education levels increase recycling. Hong et al. (1993) use self-reported survey data to

\footnotetext{
${ }^{1}$ The eleven states with bottle bills are: Oregon (1972), Vermont (1973), Maine (1978), Michigan (1978), Iowa (1979), Connecticut (1980), Delaware (1983), Massachusetts (1983), New York (1983), California (1987), and Hawaii (2002).

${ }^{2}$ See also Sigman (1995), Fullerton and Kinnaman (1995), Palmer and Walls (1997).
} 
find that income does not affect recycling rates, but that education does increase recycling. Hong et al. (1999) use actual recycling and garbage weights to find that increases in income lead to a higher recycling rate and that education is not significant. Ferrara and Missios (2004) use individual level survey data. The proportions of the materials recycled are self-reported in their survey. They find that income decreases newspaper and plastic recycling and that post-graduate education increases recycling of newspaper, glass, and aluminum. Jenkins et al. (2003) also use individual level survey data in which the proportions of the materials recycled are self-reported. They find that income increases newspaper recycling and education level increases newspaper, glass and aluminum recycling. ${ }^{3}$ None of these studies examines deposit-refund recycling, and most rely on self-reported data.

This paper is unique because it examines the effect of recycling for cash on income rather than the effect of income on recycling. The important features of this dataset are that the data are defined at the individual level and that the recycling behavior of the individuals is observed, not self-reported. While both Fullerton and Kinnaman (1996) and Hong and Adams (1999) combine a household survey with periodic weighing of garbage and recycling bins, their studies are concerned primarily with curbside and drop-off recycling programs. This study is different because it focuses on people who are recycling specifically for a cash payment, not just leaving their recyclables on the curb. The subjects of this study may also participate in curbside recycling programs at their home and other voluntary drop-off recycling programs. In fact sixty-nine percent of the

\footnotetext{
${ }^{3}$ Reschovsky and Stone (1994) and Judge and Becker (1993) also find that education increases recycling.
} 
study participants reported having curbside recycling at their home, a number that matches curbside recycling availability for the Santa Barbara south coast. ${ }^{4}$

Although most studies show that environmental taxes are mildly regressive, this paper shows that bottle laws have the potential to increase the incomes of very low wage workers. ${ }^{5}$ If states set their bottle deposit high enough, harvesting recyclables becomes viable employment for low income households. The use of the price system as an environmental remedy is often criticized on the grounds that it leads to lower incomes for the poor because environmental taxes are regressive. In this case, however, cash recyclers can augment their incomes be redeeming more containers than just the ones they purchased. Deposit-refund recycling laws may provide a way to reduce postconsumer waste and simultaneously increase the income of low wage workers. ${ }^{6}$ This paper provides the first evidence that this happens in practice.

The rest of the paper is laid out in two sections. The first section describes the data on cash recyclers and non-recyclers and the construction of a combined dataset. The dataset of recyclers is from a July, 2002 empirical field study of recyclers and their characteristics in Santa Barbara, California. These data are the first information of their kind ever collected. Using choice-based sampling the recycling survey data are merged with Census 2000 data. The dataset provides the basis for the estimation of a discrete

\footnotetext{
${ }^{4}$ The California Beverage Container Recycling and Litter Reduction Study reported that in 1999 curbside recycling programs covered 50\% of the population of Santa Barbara County. In 2001 curbside programs in California covered $72 \%$ of single family dwellings, $58 \%$ of multi-family dwellings (2 to 4 households) and $28 \%$ of apartment units.

${ }^{5}$ D.B Suits (1977) finds that sales taxes and motor vehicle taxes are regressive. There is also current literature examining the distributional effects of a tax on gasoline, which has also been found to be a regressive tax. See Sipes and Mendelsohn (2001) and West and Williams (2004) for more discussion of this.

${ }^{6}$ In this paper the amount of beverage container materials purchased by the each household is ignored. Ashenmiller (2009) calculates the value of the collected (not purchased) beverage containers returned by cash recyclers.
} 
choice model of the decision to recycle for cash. In particular this model permits the estimation of the effects of other demographic variables on the demand for cash recycling while holding income constant. This estimation provides some insights into the characteristics of those who recycle for cash. In addition, a strong negative relationship exists between recycling and income.

The second section of the paper seeks to answer the question, how important is recycling income to low income households? The data are used to determine the total amount of recyclable materials returned to recycling centers. These totals are disaggregated both by income level and by income level and English language proficiency. Bottle laws provide a strong incentive for low wage consumers to recycle because they provide a relatively high recycling wage. The data show that recycling income provides a substantial supplemental income to a certain group of low-income people recycling for cash. The final section of the paper provides a summary and conclusions.

\section{The Determinants of Recycling for Cash}

\subsection{The Model}

What are the attributes of people who are recycling for cash? To begin thinking about a recycling wage let's start with a very simple assumption. Suppose that the amount of recycling available per day is fixed. Then the daily recycling wage is simply the value of the recycling divided by the number of people who choose to recycle on that day. Because the wage is very low, only the lowest wage people will recycle, perhaps only the homeless. In this case the only people recycling for cash would be those whose recycling wage is higher than their labor market wage. 
In practice, however, we observe other people recycling. Which suggests the wage may be high enough to encourage non-destitute people to recycle. In this case we might expect to see people recycling even though their market wage is higher than their recycling wage. Perhaps they have a constraint on the number of hours that they work, or they may work in a place where they have access to large amounts of discarded containers, such as a restaurant or hotel.

In the first two cases the decision to recycle for cash is based entirely on a person's market and recycling wages. A third case would be that perhaps people do not value their time recycling in the same way that they value their time spent in the labor market. People may actually enjoy recycling for cash. People who receive some utility from their recycling - say a nice walk on the beach - might choose to recycle even if their recycling wage was less than their market wage. ${ }^{7}$ This paper uses data on cash recyclers to build a unique dataset to examine the decision to recycle for cash. This dataset is then used to assess what characteristics predict cash recycling behavior.

\subsection{Data}

\subsubsection{The Survey of Recyclers}

In the economic literature on recycling no data are currently available that explain recycling behavior in the presence of a bottle law. The dataset used for this analysis was created specifically to address empirically the questions surrounding bottle law recycling. In particular, what are the characteristics of cash recyclers. How much money do they earn? How much of the total material recycled do they collect? From where does that material come? The survey instrument grew from these questions. The dataset is the result of one month of face-to-face surveys administered to all people returning bottles

\footnotetext{
${ }^{7}$ Formal models of each of these cases are available upon request.
} 
and cans for cash at four recycling centers. The survey was administered in Spanish and English.

The recycling centers are located in Santa Barbara and Goleta, California. In July 2002 this area had three main recycling centers and five small buyback centers in supermarket parking lots. The final survey included results from one week spent at each of the high volume recycling centers as well as one week at one of the grocery store buyback centers. All people recycling for cash at each redemption center were approached while they were waiting to check out and asked to participate in the survey. The final question of the survey was a card on which the surveyor recorded the actual cash payment or the weight of each load brought to recycling center by the survey participant. This was reported individually for each material that was recycled: aluminum, glass, and plastic.

There are three main sections in the survey. The first part of the survey asks about the recycled material and recycling activities of the respondent. The survey asks where the recycled materials are from, how much time it takes to recycle, and how far out of their way they had to travel to come to the redemption center. The second part of the survey questions the individual about his age, place of birth, educational attainment, household income, etc. The question about household income was asked using a separate card. This card categorized income levels as A: less than $\$ 10,000, B$ : $\$ 10,000$ to $\$ 25,000$, C: $\$ 25,000$ to $\$ 50,000$, D: $\$ 50,000$ to $\$ 75,000$ and E: more than $\$ 75,000$. The respondent was asked to name the letter which corresponded most closely to her household income. The third part of the survey was a card filled out by the surveyor recording either the weight by material of the recycling brought into the center, or in 
some cases the amount paid by the recycling center for each material recycled. Six hundred and sixty participants completed the survey and about one third of them took the survey in Spanish. The refusal rate was ten percent.

The challenge is that the recycling survey data are only a sample of the total population that recycled for cash on the Santa Barbara South Coast. The sample was then weighted to approximate the total number of people who recycle for cash over the course of a year. Because the recycling centers were surveyed for one month, a week at each of five centers, the data represents only a of the total number of people who recycle over the course of a year. In order to estimate this number each of the cash recyclers in the sample based is weighted based on the frequency with which they recycle. ${ }^{8}$ The one assumption made, to do this, is that each recycling center was surveyed on a representative week. Each observation is then weighted based on the probability that they were surveyed. So, for example, if a person recycled once a week or more then his weight is 1 . A person who reported that they recycled once a year has a sample weight of 52 - under the assumption that they are representative of people who recycle once a year. Following this weighting system a person who reported that they recycled once a month has a weight of 52/12. About eight percent of population of the Santa Barbara South Coast brings materials to a redemption center for cash at least once a year. It is important to note that this is not an assumption that the recycling supply is constant, only an assumption that the proportions of people recycling at the center, the types of recyclers, remain constant in frequency throughout the year. This assumption is easier in Santa

\footnotetext{
${ }^{8}$ Manski and Lerman (1977) explain this technique thoroughly.
} 
Barbara where there is very little seasonality in weather. Detailed information about the weight of the total materials recycled is included in section 3.

\subsubsection{Choice Based Sample}

If eight percent of the people in the Santa Barbara south coast area recycle for cash, this leaves us with ninety-two percent of the population not recycling for cash. The survey data described above contains detailed information on the people who are recycling for cash. It does not, however, contain any information about people who do not choose to recycle for cash. In order to examine the determinants of the decision to recycle for cash, it is necessary to have individual level data on both recyclers and nonrecyclers. Data from the 2000 census 5\% sample is used to gather information on nonrecyclers. ${ }^{9}$

Both the recycling data and the census data are weighted samples. In order to merge these datasets the samples need to be re-weighted. The new weights will correct the fact that the cash recyclers in the recycling survey are also accounted for in the census sample, to be sure that the survey respondents are not counted twice in the combined dataset. The first step involves matching each observation from the recycling survey sample to an observation from the census. Propensity score matching was used in order to determine which of the observations from the census data most closely match the observations from the recycling survey data. ${ }^{10}$ Matching on the propensity score is matching on the probability of recycling conditional on the covariates. This probability is an index of all the covariates and a way of compressing the vector of covariates into a

\footnotetext{
${ }^{9}$ The 2000 Census 5\% sample is the smallest census area that surrounds the Santa Barbara south coast. This is the Census Public Use Micro Area (PUMA) which includes part of Santa Barbara County including Santa Barbara, Goleta CPD, Isle Vista CPD, Carpinteria, Montecito CDP, Mission Canyon CDP, Summerland CDP and Toro Canyon CDP.

${ }^{10}$ Rosenbaum and Rubin (1983) lays out this approach in detail.
} 
simple scalar. The identifying assumption is that the treatment, in this case recycling, is associated only with observable variables. ${ }^{11}$

The propensity score matching and re-weighting of the samples is implemented in two steps. First the propensity score is obtained by estimating a probit model for recycling using the explanatory variables in the sample. Second, using the nearestneighbor method census observations are matched to recycling observations. The census data is then re-weighted by subtracting from the original census weight the frequency that each census observation was matched to a recycling survey observation. In every case the resulting weight remained positive. There were no observations in the census that were matched to more recycling observations than the value of the observation's original weight.

\subsection{A Probit Model}

What are the attributes of people recycling for cash? In order to answer this question the dataset is used to estimate a probit model of the decision to cash recycle. The probability of recycling is assumed to be given by:

$\operatorname{Pr}($ Recycling $)=\operatorname{Pr}\left(R_{i}=1\right)=\operatorname{Pr}\left(\alpha \ln y_{i}+\beta X_{i}+v_{i}>0\right)=\Phi\left(\alpha \ln y_{i}+\beta X_{i}\right)$

where $\Phi$ is the standard normal cumulative density function. The model includes household income $\left(y_{i}\right)$ and a vector $\left(X_{i}\right)$ of demographic, household and other characteristics that may reflect the individuals' preferences and costs associated with recycling at the recycling center and may therefore explain their recycling behavior.

The variables in the regression include the natural log of income, which should represent the opportunity cost of the time spent collecting and bringing the materials to

\footnotetext{
${ }^{11}$ Heckman and Robb (1985) explains this assumption thoroughly.
} 
the recycling center for payment, as opposed to placing them in curbside garbage or recycling bins. The other variables include educational attainment dummy variables: whether the recycler has some high school education or attended college. A high level of educational attainment may lead to a higher preference for voluntary recycling, but it should not lead to a higher level of paid recycling. The regression also includes individual characteristics including whether the survey was administered in Spanish, the recycler's sex, age, and marital status. Finally, household characteristics such as household size and children under the age of 18 are also included in the regression.

\subsection{Results}

Table 1 reports the results of a probit model to identify characteristics that determine whether or not a person will choose to recycle for cash. The first two columns report the results from the combined census and recycling survey dataset. The second two columns report the results from the dataset using the corrected choice-based sampling weights.

In the first and third columns the income variable used is the natural $\log$ of income. In the second and fourth columns the income variable is the error term from an ordinary least squares regression of income on the demographic characteristics. The residual here represents the portion of income not explained by the demographic characteristics in the dataset. This allows us to interpret the significance of the impact of the demographic variables on the recycling choice, separate from their impact on the recycling choice through income.

Table 1 shows that income is negatively correlated to recycling for cash. The higher income you have, the more costly the time spent going to the recycling center, and 
the more likely you are to recycle in other, less time-consuming ways. The education variables are not significant. This is consistent with the idea that education should not determine paid recycling behavior. The primarily Spanish speakers are more likely to recycle for cash, which may reflect fewer labor market. Women are less likely to recycle for cash. Married people and older people are more likely to recycle for cash.

The most compelling result of the probit model is that income has a strong negative effect on the decision to recycle for cash. This suggests that low income people are much more likely to participate in the cash recycling program than are high income people. In fact bottle laws provide a very strong incentive for low wage consumers to recycle because they provide a relatively high wage to low income workers who recycle. How important is the recycling income for these low income recyclers? Is there a significant effect on income distribution?

\section{The Value of Recycling Income to Households and the Effect on the Income Distribution}

Under a bottle law consumers pay a deposit when they purchase a beverage container and receive a refund when they return the container to a recycling center. When a consumer chooses not to participate in the cash recycling program, the effective result is that the deposit becomes a tax. The probit model of the decision to participate in the cash recycling program shows that low-income households are more likely to participate than are high-income households. In fact data from the recycling survey show that low-income households actually recycle more material than they purchase. What additional data are necessary to examine the size of the income redistribution from the 
consumers who pay the deposit but don't collect the refund to recyclers who collect other people's refunds?

\subsection{Data on the Total Weight of Recycling for 2002}

In order to determine the importance of recycling income to people participating in the California Cash Redemption Program we need the annual cash value of the recycling income. The recycling survey data reports the total amount of materials redeemed for cash at each of four recycling centers for a period of one week each. To find the annual value of recycling income the data from the survey is combined with the total amount of recycled materials for the Santa Barbara South Coast. ${ }^{12}$

The following method was used to aggregate the numbers from the survey up to the total weight of recycled materials for the year. From the survey data was used to calculate the proportions of aluminum, glass, and plastic materials brought to the redemption centers by the recyclers of each income level. This is done a second time by income level and language proficiency. It is assumed that the percentages of the weight of the materials (not the actually weights of the materials) redeemed by each recycler type in the month of July are representative throughout the year. The disaggregated data are proprietary, but to give you an example the average amount of aluminum for the larger centers was over 9.5 tons and for the supermarket buybacks the average was about 1.5 tons. For glass the averages are approximately 75 tons and 2 tons. For plastic they are about 3.5 tons and 1.5 tons. In addition, while the survey included all three of the high volume redemption centers in the region, it only included one of the four much smaller

\footnotetext{
${ }^{12}$ The Santa Barbara South Coast is defined as the city of Santa Barbara, Goleta CDP and Isla Vista CDP. A census-designated place (CDP) is an area identified by the United States Census for separate statistical reporting. The household income question is included on the census long form and the distribution is estimated from the sample of households who answer this form and is only an estimate.
} 
volume supermarket buyback centers. The buyback center was chosen to be representative of the four supermarket buyback centers. The assumption is then made that the proportion of recyclables brought by recyclers of each income level is the same at each of the four supermarket buyback centers. These proportions are then applied to the actual total amount of material collected by each recycling center during the 2002 calendar year that it was survey. ${ }^{13}$ There is some seasonality in the weight of the total CRV recycling reporting by month in the data. The total weight of CRV recycling in 2002 ranges from a low in April of 296,167 pounds to a high in September of 881,192 pounds. The two highest months are September and October, often the hottest months in Santa Barbara. The average weight of recycling in a month is 566,438 pounds and the total weight of the CRV recycling in July, 2002 was 506,658 pounds. ${ }^{14}$

Using the proportion of materials redeemed at recycling center limits the total amount of recycling to the actual amount of material recycled in 2002. This is important because the next step is to calculate the value of the total amount of materials recycled in 2002. To determine the total amount of cash paid for recycled materials the per pound redemption value paid by the State of California in the year 2002 was used. The redemption values were $\$ 0.77$ for a pound of aluminum, $\$ 0.05$ for a pound of glass, and $\$ 0.41$ for a pound of plastic. ${ }^{15}$

\footnotetext{
${ }^{13}$ The total amount of recycling collected by each recycling center was supplied by the California Department of Conservation, Division of Recycling.

${ }^{14}$ Occasionally recycling centers save up their aluminum for two months and report no aluminum in one month. In these cases the aluminum is assumed to have been collected over two months and the totals are adjusted.

${ }^{15}$ These values are lower than the true values since the redemption centers pay a slightly elevated price for larger loads of aluminum. For example, all the redemption centers pay $\$ 1.00$ a pound for a load of aluminum larger than a 100 lbs.
} 


\subsection{Results}

Table 2 reports the breakdown of participation in the California Cash Redemption Program (CRV recycling) and the weight of the materials by household income. The participation rate in the program is skewed toward the lower income levels. Twelve percent of the people who earn less than $\$ 10,000$ a year and thirteen percent of the people who earn between $\$ 10,000$ and $\$ 24,999$ recycle, compared to nine percent of people who earn between $\$ 25,000$ and $\$ 49,999$, five percent of the people who earn between $\$ 50,000$ and $\$ 75,000$ and four percent of the people who earn over $\$ 75,000$. Recyclers with incomes less than $\$ 25,000$ are responsible for fifty-six percent of the aluminum recycled, sixty percent of the glass recycled, sixty-six percent of the plastic recycled, and sixty percent of all recycled materials by weight.

Table 3 reports the cash value of the redeemed CRV materials by income level. The recyclers with incomes less than $\$ 25,000$ received $\$ 608,649$ during 2002, which was fifty-eight percent of the value of all of the recycling brought to the redemption centers. The average cash payment per household is the total value of the recyclable materials returned by household in each income bracket divided by the total number of households. The payments to households earning less than $\$ 25,000$ is about $\$ 40$, while for the higher income levels the annual payments drop to $\$ 14, \$ 10$, and $\$ 5$. The average cash paid to all recycling households is the total value of the recyclable materials returned by household in each income bracket divided by the total number of recycling households. The payment to households earning less than $\$ 10,000$ is about $\$ 340$ while households earning between $\$ 10,000$ and $\$ 24,999$ receive about $\$ 315$. For the three higher income levels the payments drop to $\$ 144, \$ 217$, and $\$ 124$. 
Table 4 reports the breakdown of 2002 participation in the California Cash Redemption Program and the weight of the total materials recycled by income level and whether the primary language of the recycler is Spanish. For primarily English speakers four percent of the people who earn less than $\$ 10,000$ a year and three percent of the people who earn between $\$ 10,000$ and $\$ 24,999$, and between $\$ 25,000$ and $\$ 49,999$, recycle for cash. This is compared to two percent of English speakers who earn between $\$ 50,000$ and $\$ 75,000$ and one percent of those who earn over $\$ 75,000$.

For primarily Spanish speakers the percentage of households that recycle is significantly higher. Twenty-six percent of primarily Spanish speakers earning less than $\$ 10,000$ a year and twenty-five percent of Spanish speakers earning between $\$ 10,000$ and \$24,999 recycle for cash. The participation rate for Spanish speakers then drastically drops to only six percent of those earning between $\$ 25,000$ and $\$ 49,999$, one percent of those earning between $\$ 50,000$ and $\$ 75,000$ and less than one percent of those earning over $\$ 75,000$.

Primarily English speaking recyclers with incomes less than $\$ 25,000$ are responsible for eighteen percent of the aluminum recycled, twenty-seven percent of the glass recycled, twenty-seven percent of the plastic recycled, and twenty-six percent of all recycled materials by weight. Primarily Spanish speaking recyclers with incomes less than $\$ 25,000$ are responsible for thirty-eight percent of the aluminum recycled, thirtythree percent of the glass recycled, forty percent of the plastic recycled, and thirty-four percent of all recycled materials by weight.

Table 5 reports the cash value for the year 2002 of the CRV recycling returned by income level and whether the primary language of the recycler is Spanish. The primarily 
English speaking recyclers with incomes less than \$25,000 received \$222,759 during 2002, which was twenty-two percent of the value of all of the recycling brought to the redemption centers. The primarily Spanish speaking recyclers with incomes less than $\$ 25,000$ received $\$ 385,889$ during 2002, which was thirty-seven percent of the value of all of the recycling brought to the redemption centers.

The average cash payment per household is the total value of the recyclable materials returned by households in each income bracket divided by the total number of households in that income bracket, based on the primary language. The payments to primarily English speaking households earning less than $\$ 10,000$ is $\$ 10.51$ per year, while the payments to primarily Spanish speaking households earning less than $\$ 10,000$ is $\$ 110.95$ per year. The payment to primarily English speaking households earning between $\$ 10,000$ and $\$ 24,999$ is $\$ 6.60$ per year, while the payment to primarily Spanish speaking households earning between $\$ 10,000$ and $\$ 24,999$ is $\$ 107.61$ per year. The payments to primarily English speaking households for the higher income levels continue to drop to $\$ 3.73, \$ 3.68$, and $\$ 1.44$. Primarily Spanish speaking households face a much larger drop at higher income levels to $\$ 16.50, \$ 1.64$, and $\$ 0.20$.

The average cash paid to all recycling households is the total value of the recyclable materials returned by household in each income and language bracket divided by the total number of recycling households in that bracket. At income levels below $\$ 50,000$ the average cash payment to primarily Spanish speaking recycling households is approximately twice the cash payment to primarily English speaking households. The payment to households earning less than $\$ 10,000$ is $\$ 278$ for English speaking households and \$428 for Spanish speaking households. For households earning between 
$\$ 10,000$ and $\$ 24,999, \$ 200$ goes to English speaking households and $\$ 423$ goes to Spanish speaking households. For households earning between $\$ 25,000$ and $\$ 49,999$, \$115 goes to English speaking households and \$264 goes to Spanish speaking households. For households with income between $\$ 50,000$ and $\$ 74,999$ the payments are about equal at \$216 for English speaking households and \$257 for Spanish speaking households. For households with incomes over $\$ 75,000$, the payment to English speaking households is twice the payment to Spanish speaking households, \$124 compared to $\$ 61$.

\section{Conclusions}

A strongly negative correlation between income and participating in a depositrefund program exists. This is in contrast to the inconclusive findings in the literature review concerning the relationship between income and recycling. Other determinants such as gender, age, language, and the presence of children are also significant. The simplest model to describe cash recycling may not be perfect, but it is a strong start. However it may be true that in the case of cash recycling people may not value their time recycling in the same way as they value time in their labor market job.

The key to the income redistribution, from the consumers who pay the deposit but don't collect the refund to recyclers who collect other people's refunds, is that the low income families are both more likely to recycle for cash, and receive rebates for more materials than they purchase and higher income families are more likely to recycle their materials through household curbside recycling programs. The survey showed that low income households return materials to the recycling center for cash that they did not purchase. People who reported that at least half of the material they were paid did not 
come from their own home or business represented $28.8 \%$ of the total weight of CRV recycling during the time of the survey. ${ }^{16}$ This is an underestimate because recyclers whose primary recycling was from their home or workplace, but who in fact did also bring in additional materials that they did not purchase, are not included in that number. The method of recycling, cash versus curbside, leaves unaffected the gross consumption of recyclable material. In fact, as beverage container commodities are normal goods, then the fact that there exists an income redistribution can not be questioned. ${ }^{17}$ This paper is the first empirical estimation of the value of this income redistribution. The scavenging of bottle and cans to return for the deposit creates a situation in which deposit-refund recycling laws improve resource allocation using the appropriate Pigouvian tax and simultaneously increase the income of very low wage workers.

Lower income households recycle for cash more than households with higher incomes. While the cash transfers are small numbers and do not represent a large change in the income distribution. The more important question from a policy perspective is whether the recycling income is significant. Twelve percent of households with an income less than $\$ 10,000$ participate in the California Cash Redemption Program. These households comprise about one percent of the total households in the Santa Barbara South Coast and yet they receive about twenty percent of the total cash value of recycling in 2002. Assuming the average household income for these households is $\$ 5,000$, then a $\$ 340$ annual transfer represents 6.8 percent of annual income. When we narrow our focus to primarily Spanish speaking the transfer is even greater. Twenty-six percent of primarily Spanish speaking households earning less than $\$ 10,000$ receive about $\$ 428$ a

\footnotetext{
${ }^{16}$ Ashenmiller (2009)

${ }^{17}$ Several studies find that beer, soda and juices are normal goods. See Johnson et al (1992), Selvanathan, S. (2006)
} 
year from cash recycling. Assuming the average household income for these households is $\$ 5,000$, then a $\$ 428$ annual transfer represents 8.6 percent of annual income. So while the overall effect of the deposit refund for many income levels may be very small, for the people falling into the lowest income bracket it is quite meaningful. The Santa Barbara area has a very large number of primarily Spanish speaking families. Recyclers are not required to show any form of identification. In other words, being an illegal worker cannot prevent you from recycling for cash. The Bottle Law provides a significant income transfer to a small number of households that are difficult to support. 


\section{References}

Ashenmiller, Bevin, Cash Recycling, Waste Disposal Costs and the Incomes of the Working Poor: Evidence from California, Land Economics, forthcoming (August, 2009).

Coase, R.H., The Problem of Social Cost, Journal of Law and Economics, 3 (October, 1960), 1-44.

Callan, Scott J. and Janet M. Thomas, The Impact of State and Local Policies on the Recycling Effort, Eastern Economic Journal, 23 (Fall 1997), 411-423.

Dehejia, Rajeev H. and Sadek Wahba, Propensity Score Matching Methods for Nonexperimental Causal Studies, The Review of Economics and Statistics, 84 (February 2002), 151-161.

Duggal, Vijaya, Cynthia Saltzman, and Mary L. Williams, Recycling: An Empirical Analysis, Eastern Economic Journal, 17 (July-September 1991), 351-358.

Ferrara, Ida and Paul Missios, Recycling and Waste Diversion Effectiveness: Evidence from Canada, working paper.

Fullerton, Don and Thomas C. Kinnaman, The Economics of Residential Solid Waste Management, NBER Working Paper 7326, 1999. 
Fullerton, Don and Thomas C. Kinnaman, Garbage, Recycling, and Illicit Burning or Dumping, Journal of Environmental Economics and Management, 29 (1995), 78-91.

Fullerton, Don and Thomas C. Kinnaman, Household Responses to Pricing Garbage by the Bag, American Economic Review, 86 (September 1996), 971-984.

Fullerton, Don and Sarah West, Can Taxes on Cars and on Gasoline Mimic an Unavailable Tax on Emissions? Journal of Environmental Economics and Management 43 (January 2002) 135-157.

Fullerton, Don and Ann Wolverton, Two Generalizations of a Deposit-Refund System, AEA Papers and Proceedings, 90 (May 2000), 238-242.

Heckman, James and R. Robb, Alternative Methods for Evaluating the Impact of Interventions, in J. Heckman and B. Singers (Eds.), Longitudinal Analysis of Labor Market Data, Econometric Society Monograph, Vol. 10, Cambridge University Press, Cambridge, U.K., 1985.

Hong, Seonghoon and Richard M. Adams, An Economic Analysis of Household Recycling of Solid Wastes: The Case of Portland, Oregon, Journal of Environmental Economics and Management, 25 (September 1993), 278-282. 
Hong, Seonghoon and Richard M. Adams, Household Responses to Price Incentives for Recycling: Some Further Evidence, Land Economics, 75 (November 1999), 505-514.

Jenkins, Robin R., Salvador A. Martinez, Karen Palmer, and Michael J. Podolsky, The determinants of household recycling: a material-specific analysis of recycling program features and unit pricing, Journal of Environmental Economics and Management, 45 (2003), 294-318.

Johnson, James A., Ernest H. Oksanen, Michael R. Veall and Deborah Fretz, Short-Run and Long-Run Elasticities for Canadian Consumption of Alcoholic Beverages: an ErrorCorrection Model, The Review of Economics and Statistics, 74 (1), (1992), 64-74.

Judge, Rebecca and Anthony Becker, Motivating Recycling: A Marginal Cost Analysis, Contemporary Policy Issues, 11 (July 1993), 58-68.

Manski, Charles F. and Steven R. Lerman, The Estimation of Choice Probabilities from Choice Based Samples, Econometrica, 45 (November 1977), 1977-1988.

Palmer, Karen and Margaret Walls, Optimal Policies for Solid Waste Disposal Taxes, Subsidies, and Standards, Journal of Public Economics, 65 (1997), 193-205.

Pigou, A.C., The Economics of Welfare, $4^{\text {th }}$ edition, London, 1932. 
Reschovsky, James D. and Sarah E. Stone, Market Incentives to Encourage Household Waste Recycling: Pay for What You Throw Away, Journal of Policy Analysis and Management, 13, (1994), 120-139.

Rosenbaum, Paul R. and Donald B. Rubin, The Central Role of the Propensity Score in Observational Studies for Causal Effects, Biometrika, 70 (1983), 41-55.

Selvanathan, S., Consumption Patterns of Food, Tobacco and Beverages: A CrossCountry Analysis, Applied Economics, 13 (2006), 1567.

Sigman, Hilary, Midnight Dumping, RAND Journal of Economics, 29 (Spring 1998), 157-178.

Sipes, Kristin N. and Robert Mendelsohn, The Effectiveness of Gasoline Taxation to Manage Air Pollution, Ecological Economics, v36 (February 2001), 299-309.

Suits, Daniel B., Measurement of Tax Progressivity, American Economics Review, 67 (1977), 747-752.

West, Sarah E. and Roberton C. Williams, Estimates from a consumer demand system: implications for the incidence of environmental taxes, Journal of Environmental Economics and Management 47 (2004) 535-558. 
Table 1: The Determinants of Recycling

(Probit Marginal Effects and Standard Errors)

\begin{tabular}{|c|c|c|c|c|}
\hline & \multicolumn{2}{|c|}{ Census and Sample Weights } & \multicolumn{2}{|c|}{ Choice Based Sample Weights } \\
\hline & Recycle & Recycle & Recycle & Recycle \\
\hline \multirow[t]{2}{*}{ Natural log of Income } & $-0.443^{* * *}$ & & $-0.447 * * *$ & \\
\hline & $(0.045)$ & & $(0.045)$ & \\
\hline \multirow[t]{2}{*}{ Residuals of Income Equation ${ }^{1}$} & & $-0.443 * * *$ & & $-0.447 * * *$ \\
\hline & & $(0.045)$ & & $(0.045)$ \\
\hline \multirow[t]{2}{*}{ Born in US } & $0.208^{* *}$ & 0.123 & $0.213^{* *}$ & 0.127 \\
\hline & $(0.086)$ & $(0.086)$ & $(0.087)$ & $(0.086)$ \\
\hline \multirow[t]{2}{*}{ No High School } & -0.025 & -0.007 & -0.025 & -0.007 \\
\hline & $(0.112)$ & $(0.112)$ & $(0.112)$ & $(0.112)$ \\
\hline \multirow[t]{2}{*}{ Some College or More } & -0.028 & -0.092 & -0.054 & -0.093 \\
\hline & $(0.091)$ & $(0.113)$ & $(0.113)$ & $(0.113)$ \\
\hline \multirow[t]{2}{*}{ Spanish language survey } & $0.753^{* * *}$ & $0.892 * * *$ & $0.769 * * *$ & $0.907 * * *$ \\
\hline & $(0.127)$ & $(0.127)$ & $(0.127)$ & $(0.128)$ \\
\hline \multirow[t]{2}{*}{ Female } & $-0.481^{* * *}$ & $-0.463^{* * *}$ & $-0.486^{* * *}$ & $-0.467 * * *$ \\
\hline & $(0.070)$ & $(0.070)$ & $(0.070)$ & $(0.070)$ \\
\hline \multirow[t]{2}{*}{ Married } & $0.355^{* * *}$ & $0.239 * * *$ & $0.360 * * *$ & $0.242 * * *$ \\
\hline & $(0.075)$ & $(0.074)$ & $(0.075)$ & $(0.074)$ \\
\hline \multirow[t]{2}{*}{ Age } & $0.005 * * *$ & $0.004^{* *}$ & $0.005^{* * *}$ & $0.004^{* *}$ \\
\hline & $(0.002)$ & $(0.002)$ & $(0.002)$ & $(0.002)$ \\
\hline \multirow[t]{2}{*}{ Child under 18 in house } & $-0.162 *$ & $-0.216^{* *}$ & $-0.163 *$ & $-0.217 * *$ \\
\hline & $(0.088)$ & $(0.087)$ & $(0.088)$ & $(0.088)$ \\
\hline \multirow[t]{2}{*}{ Household Size } & -0.005 & $-0.036^{* *}$ & -0.006 & $-0.037 * *$ \\
\hline & $(0.018)$ & $(0.018)$ & $(0.018)$ & $(0.018)$ \\
\hline Obs. & 9395 & 9395 & 9395 & 9395 \\
\hline Pseudo $\mathrm{R}^{2}$ & 0.125 & 0.125 & 0.127 & 0.127 \\
\hline
\end{tabular}

Notes: Robust standard errors are in parentheses. Regression includes a constant term.

***, **, and * are significance at the $1 \%, 5 \%$ and $10 \%$ level respectively. ${ }^{1}$ These are the residuals from an OLS regression of the natural log of income on the demographic variables. 
Table 2: The 2002 Breakdown of CRV1 Recycling Participation and Weight by Income Level

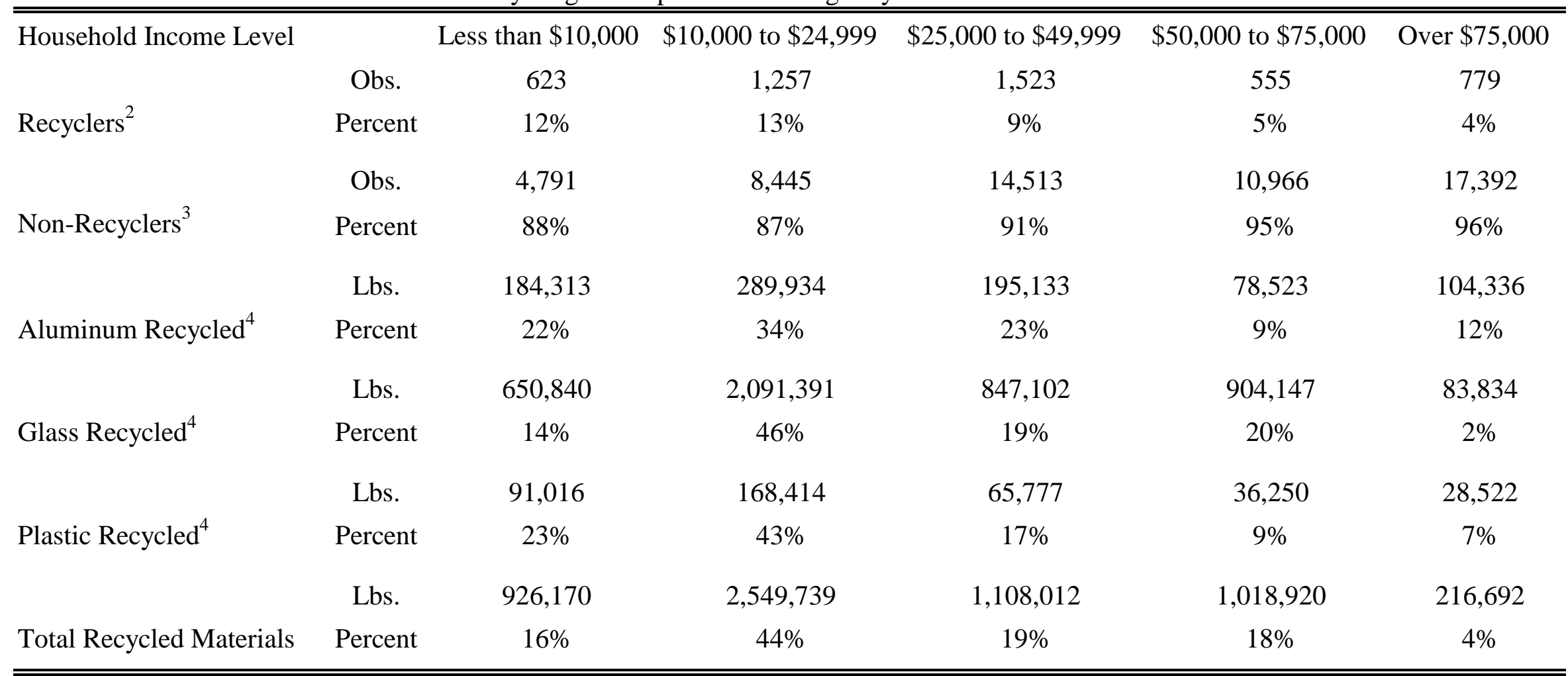

Notes: ${ }^{1} \mathrm{CRV}$ are bottles and cans that are included in the California Cash Redemption program. ${ }^{2}$ These are the corrected sample weights from the recycling survey which estimate the total number of recyclers in a year from each income level. ${ }^{3}$ This is the total number of households reported for each of these income levels in the 2000 Census for Santa Barbara city, Goleta CDP and Isla Vista CDP (income is estimated from the Census long form which is a sample of 1 out of 6 households), minus the recycling households. ${ }^{4}$ In order to report these estimates I assume that the proportion of the recycling brought by each income level to each of the recycling centers is the same for the month of July as it was for the week the center was surveyed. In addition I assume that all of the grocery store parking lot recycling center have the same proportions as the one that was in the survey. These proportions are then applied to total recycling weights supplied by the Santa Barbara County Department of Public Works, Solid Waste and Utilities Divison. The number for glass reported in this chart is the estimated amount of CRV glass captured by the curbside recycling program for all of Santa Barbara County and was supplied by the California Department of Conservation, Division of Recycling. This number is an upper bound because it was not possible to secure the amount of CRV glass in the South Coast recycling region. 
Table 3: 2002 Cash Value of $\mathrm{CRV}^{1}$ Recycling by Income Level

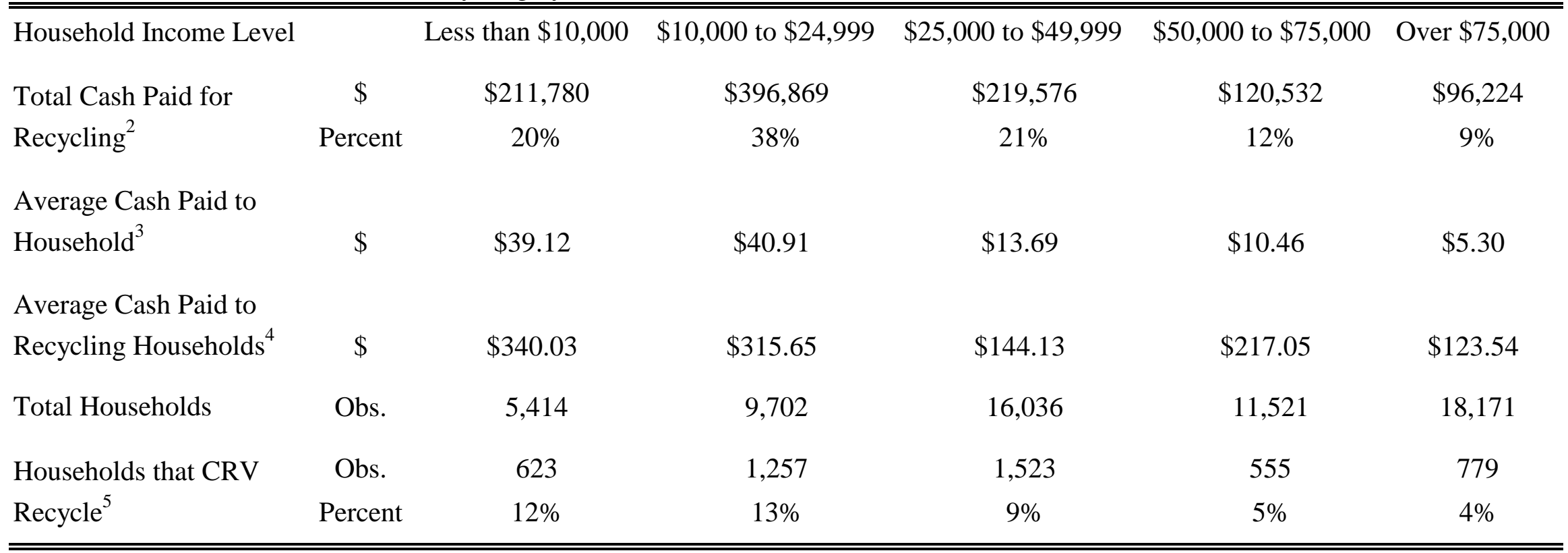

Notes: ${ }^{1}$ CRV are bottles and cans that are included in the California Cash Redemption program. ${ }^{2}$ The total cash paid for recycling is the value of the total amount of recycling for the South Coast in Table $1 .{ }^{3}$ The average cash paid to each household is the total value of all the cash recycling divided by the number of people in each income bracket based on the 2000 Census information for Santa Barbara city, Goleta CDP and Isla Vista CDP. The income question is on the Census long form and therefore is estimated from a sample ( 1 in 6 households). ${ }^{4}$ The average cash paid to recycling households is the total value of the recycling returned divided by the estimated number of households that participates in the CRV recycling program. ${ }^{5}$ The estimate of the number of households that participate in CRV recycling is based on the frequency that recyclers reported they came to the recycling center. 
Table 4: The 2002 Breakdown of CRV ${ }^{1}$ Recycling Participation and Weight by Income Level and Language Proficiency

\begin{tabular}{|c|c|c|c|c|c|c|c|c|c|c|c|}
\hline \multirow{2}{*}{$\begin{array}{l}\text { Household Income Level } \\
\text { Language }^{2}\end{array}$} & & \multicolumn{2}{|c|}{ Less than $\$ 10,000$} & \multicolumn{2}{|c|}{$\$ 10,000$ to $\$ 24,999$} & \multicolumn{2}{|c|}{$\$ 25,000$ to $\$ 49,999$} & \multicolumn{2}{|c|}{$\$ 50,000$ to $\$ 75,000$} & \multicolumn{2}{|c|}{ Over $\$ 75,000$} \\
\hline & & English & Spanish & English & Spanish & English & Spanish & English & Spanish & English & Spanish \\
\hline \multirow[t]{2}{*}{ Recyclers $^{3}$} & Obs. & 364 & 259 & 607 & 650 & 1,228 & 295 & 540 & 15 & 770 & 9 \\
\hline & Percent & $4 \%$ & $26 \%$ & $3 \%$ & $25 \%$ & $3 \%$ & $6 \%$ & $2 \%$ & $1 \%$ & $1 \%$ & $0.3 \%$ \\
\hline \multirow[t]{2}{*}{ Non-Recyclers ${ }^{3}$} & Obs. & 9,252 & 739 & 17,838 & 1,907 & 36,706 & 4,428 & 31,167 & 2,353 & 65,816 & 2,672 \\
\hline & Percent & $96 \%$ & $74 \%$ & $97 \%$ & $75 \%$ & $97 \%$ & $94 \%$ & $98 \%$ & $99 \%$ & $99 \%$ & $99.7 \%$ \\
\hline \multirow[t]{2}{*}{ Aluminum Recycled ${ }^{4}$} & Lbs. & 81,414 & 102,899 & 71,760 & 218,174 & 131,920 & 63,213 & 74,437 & 4,085 & 103,646 & 690 \\
\hline & Percent & $9.6 \%$ & $12.1 \%$ & $8.4 \%$ & $25.6 \%$ & $15.5 \%$ & $7.4 \%$ & $8.7 \%$ & $0.5 \%$ & $12.2 \%$ & $0.1 \%$ \\
\hline \multirow[t]{2}{*}{ Glass Recycled ${ }^{4}$} & Lbs. & 414,903 & 235,937 & 829,021 & $1,262,370$ & 424,799 & 422,302 & 890,372 & 13,775 & 83,834 & 0 \\
\hline & Percent & $9.1 \%$ & $5.2 \%$ & $18.1 \%$ & $27.6 \%$ & $9.3 \%$ & $9.2 \%$ & $19.5 \%$ & $0.3 \%$ & $1.8 \%$ & $0 \%$ \\
\hline \multirow[t]{2}{*}{ Plastic Recycled ${ }^{4}$} & Lbs. & 43,048 & 47,969 & 60,899 & 107,515 & 45,924 & 19,853 & 36,108 & 142 & 28,522 & 0 \\
\hline & Percent & $11.0 \%$ & $12.3 \%$ & $15.6 \%$ & $27.6 \%$ & $11.8 \%$ & $5.1 \%$ & $9.3 \%$ & $0.04 \%$ & $7.3 \%$ & $0 \%$ \\
\hline \multirow[t]{2}{*}{ Total Recycled Materials } & Lbs. & 539,365 & 386,805 & 961,681 & $1,588,058$ & 602,644 & 505,369 & $1,000,918$ & 18,002 & 216,002 & 690 \\
\hline & Percent & $9 \%$ & $7 \%$ & $17 \%$ & $27 \%$ & $10 \%$ & $9 \%$ & $17 \%$ & $0.3 \%$ & $4 \%$ & $0.01 \%$ \\
\hline
\end{tabular}

Notes: ${ }^{1} \mathrm{CRV}$ are bottles and cans that are included in the California Cash Redemption program. ${ }^{2}$ The language assigned to each household is based on the whether they reported that their first or most spoken language was Spanish and they spoke English "not well" or "not at all". These are people who took the recycling survey in Spanish. ${ }^{3}$ These numbers are based on the corrected sample weights from the US Census and the recycling survey. ${ }^{4}$ To find these values I assume that the proportion of the recycling brought by each income level to each of the recycling centers is the same for the month of July as it was for the week the center was surveyed. In addition I assume that all of the grocery store parking lot recycling center have the same proportions as the one that was in the survey. These proportions are then applied to total recycling weights supplied by the Santa Barbara County Department of Public Works, Solid Waste and Utilities Divison. The number for glass reported in this chart is the estimated amount of CRV glass captured by the curbside recycling program for all of Santa Barbara County and was supplied by the California Department of Conservation, Division of Recycling. This number is an upper bound because it was not possible to secure the amount of CRV glass in the South Coast recycling region. 
Table 5: 2002 Cash Value of $\mathrm{CRV}^{1}$ Recycling by Income Level and Language

\begin{tabular}{|c|c|c|c|c|c|c|c|c|c|c|c|}
\hline \multirow{2}{*}{$\begin{array}{l}\text { Household Income Level } \\
\text { Language }^{2}\end{array}$} & & \multicolumn{2}{|c|}{ Less than $\$ 10,000$} & \multicolumn{2}{|c|}{$\$ 10,000$ to $\$ 24,999$} & \multicolumn{2}{|c|}{$\$ 25,000$ to $\$ 49,999$} & \multicolumn{2}{|c|}{$\$ 50,000$ to $\$ 75,000$} & \multicolumn{2}{|c|}{ Over $\$ 75,000$} \\
\hline & & English & Spanish & English & Spanish & English & Spanish & English & Spanish & English & Spanish \\
\hline Total Cash Paid for & $\$$ & $\$ 101,084$ & $\$ 110,696$ & $\$ 121,675$ & $\$ 275,193$ & $\$ 141,647$ & $\$ 77,929$ & $\$ 116,640$ & $\$ 3,892$ & $\$ 95,693$ & $\$ 531$ \\
\hline Recycling $^{3}$ & Percent & $10 \%$ & $11 \%$ & $12 \%$ & $26 \%$ & $14 \%$ & $7 \%$ & $11 \%$ & $0.37 \%$ & $9 \%$ & $0.05 \%$ \\
\hline $\begin{array}{l}\text { Average Cash Paid to } \\
\text { Household }^{5}\end{array}$ & $\$$ & $\$ 10.51$ & $\$ 110.95$ & $\$ 6.60$ & $\$ 107.61$ & $\$ 3.73$ & $\$ 16.50$ & $\$ 3.68$ & $\$ 1.64$ & $\$ 1.44$ & $\$ 0.20$ \\
\hline $\begin{array}{l}\text { Average Cash Paid to } \\
\text { Recycling Households }\end{array}$ & $\$$ & $\$ 278$ & $\$ 428$ & $\$ 200$ & $\$ 423$ & $\$ 115$ & $\$ 264$ & $\$ 216$ & $\$ 257$ & $\$ 124$ & $\$ 61$ \\
\hline Total Households & Obs. & 9,616 & 998 & 18,445 & 2,557 & 37,934 & 4,723 & 31,707 & 2,368 & 66,586 & 2,681 \\
\hline Households that CRV & Obs. & 364 & 259 & 607 & 650 & 1,228 & 295 & 540 & 15 & 770 & 9 \\
\hline Recycle $^{4}$ & Percent & $4 \%$ & $26 \%$ & $3 \%$ & $25 \%$ & $3 \%$ & $6 \%$ & $2 \%$ & $1 \%$ & $1 \%$ & $0.3 \%$ \\
\hline
\end{tabular}

Notes: ${ }^{1}$ CRV are bottles and cans that are included in the California Cash Redemption program. ${ }^{2}$ The language assigned to each household is based on the whether they reported that their first or most spoken language was Spanish and they spoke English "not well" or "not at all". These are people who took the recycling survey in Spanish. ${ }^{3}$ The total cash paid for recycling is the value of the total amount of recycling for the South Coast in Table 3. ${ }^{4}$ The estimate of the number of households that participate in CRV recycling is based on the frequency that recyclers reported they came to the recycling center. ${ }^{5}$ The average cash paid to each household is the total value of all the cash recycling divided by the number of people in each income bracket based on the corrected sample weights from the 2000 US Census and the recycling survey. ${ }^{6}$ The average cash paid to recycling households is the total value of the recycling returned divided by the estimated number of households that participates in the CRV recycling program. ${ }^{7}$ The average cash amount paid to recycling households in the survey is the average of their project annual recycling income based on the total payment they received the day of the survey and the frequency that they report recycling. 